\title{
EDITORIAL
}

\section{The Jenner bicentenary; still uses for smallpox vaccine}

\section{Jenner's contribution to preventive medicine}

Edward Jenner performed his first vaccination, on James Phipps, on 14 May $1796[1,2]$. The centenary of that event was celebrated [3] rather than that of the publication of Jenner's famous Inquiry of 1798 [1], and that precedent is generally being followed for the bicentenary [4]. We are marking the bicentenary by publishing two Special Articles which describe how progress with poxvirus recombinant vaccines is leading to significant advances in the control of infection $[5,6]$.

In fact the vaccination of Phipps was the second, and perhaps least important, link in a series of four related events. These, taken together, represent Jenner's seminal contribution to preventive medicine, and fortuitously reflect the title of our Journal. First was the series of circumstantial epidemiological observations carried out from the late 1770 s which led Jenner to conclude that individuals who had acquired natural cowpox were subsequently resistant to natural and/or inoculated smallpox (variolation) $[1,7]$. Then came the vaccination of Phipps with material taken from the hand of Sarah Nelmes; Phipps resisted variolation. At this stage Jenner submitted a paper to the Royal Society, of which he was a Fellow, but was advised to collect more data [2]. This he did, and in May 1798 started the small but crucial series of vaccinations, the third link in the chain (Fig. 1). These showed that vaccine could be passed arm-to-arm and that those few who were tested resisted variolation. Jenner concluded that his cowpox vaccine was a safe, effective alternative to variolation, which could be maintained by arm-to-arm transfer. More controversially he concluded that the origin of his vaccine was an equine infection (grease) which was stabilized by passage through the cow, and also that his vaccine induced lifelong immunity to smallpox. At this stage he published his Inquiry [1,7].

The fourth and final link was provided in 1799 when Jenner provided guidance for those wanting to make use of vaccination. In his Further Observations [8], he compared 'true' cowpox which gave the expected result, i.e., a mild localized lesion which induced immunity to smallpox, with 'spurious' cowpox which did not produce the desired effect. In fact he recognized four varieties of spurious cowpox. In modern terms the first three corresponded to: (A) other bovine zoonoses, e.g., Milker's Nodes, which could be mistaken for cowpox; (B) abscesses caused by contaminating bacteria in cowpox material which had itself been inactivated during inappropriate storage; $(\mathrm{C})$ abscesses produced by material similarly stored but which did not originally come from a cowpox lesion. The fourth variety was another reference to inconsistent results produced by material direct from horses [7]. Jenner's concept of true and spurious cowpox was essential for any realistic appreciation of the value of vaccination, and his clear differentiation of the first three varieties, many years before the discovery of pathogenic microorganisms has rightly been described as 'masterful' [9].

The introduction of smallpox vaccination in general was opposed by variolators who feared the end of a lucrative monopoly. Jenner's claims in particular were variously opposed, and well into the 20th Century, by those who believed others had 'discovered' vaccination earlier, that his cowpox vaccine was merely attenuated smallpox virus, and that the more extensive work of others established the true worth of vaccination. This last is true, but such trials could only build on Jenner's foundations, and claims to have discovered vaccination only came to light after 1798 .

Vaccine strains were soon to be developed from both cowpox and horsepox in circumstances where smallpox virus could not have been involved and there is no doubt that Jenner's introduction of vaccination with an animal virus marked a distinct break with previous practice and experience and laid the foundations for the effective control of smallpox $[7,10]$.

Jenner's initial claims were based on only few vaccinations and he erred in his belief that his vaccine 


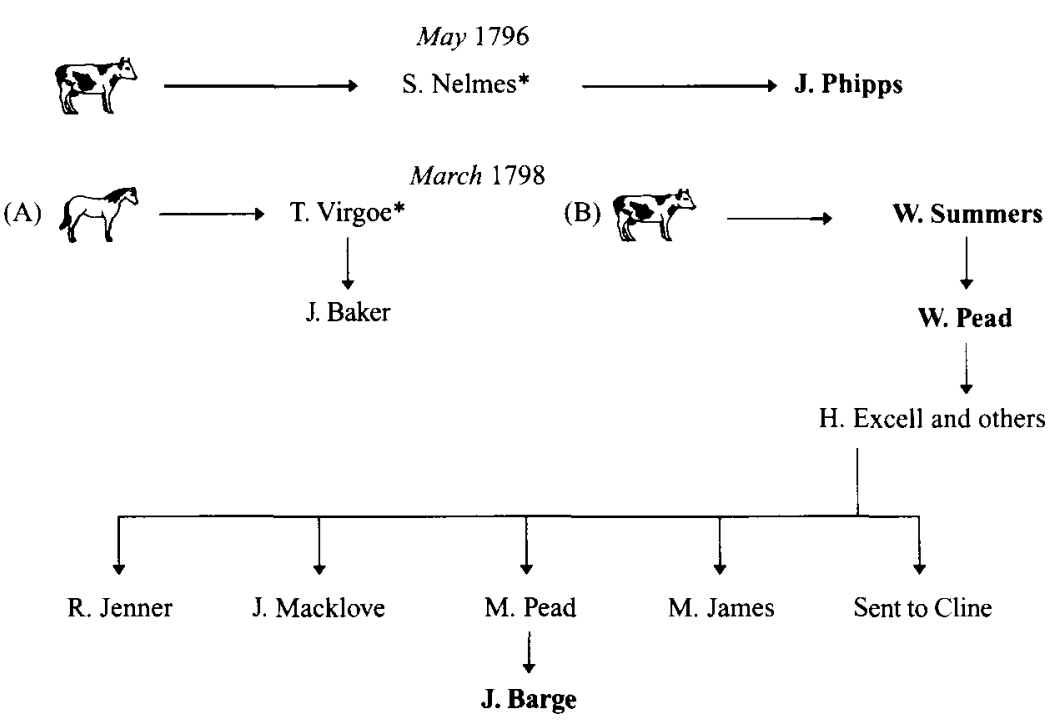

Fig. 1. Jenner's vaccinations 1796-98. *, Accidental infection. Those in bold type resisted variolation.

Table 1. Comparison of the features of non-replicating expression vectors (NREV) and infectious and non-infectious vaccines

\begin{tabular}{|c|c|c|c|}
\hline & \multicolumn{3}{|l|}{ Vaccine* } \\
\hline & Infectious & NREV & Non-infectious \\
\hline Species spectrum & Narrow & Wide & Wide \\
\hline Side effects & Higher & Low & Low \\
\hline Spread to contacts & Possible & No & No \\
\hline Single dose & Yes (?) & Yes $(?)$ & No \\
\hline Antigen amplified & Yes & Yes & No \\
\hline Antigen presentation & Good & Good & Poorer \\
\hline IgM response & Good & Good & Good \\
\hline IgA response & Good & Good & Poor \\
\hline $\mathrm{CM}$ response & Good & Good & Poor ${ }^{\dagger}$ \\
\hline
\end{tabular}

* Desirable properties in bold type.

† Some, e.g. toxoids, less dependent on cell mediated (CM) response.

conferred lifelong immunity. However, his observations were set in a sound epidemiological context and were illuminated by remarkable insight into some possible difficulties. The recognition of his contribution by objective observers as well as by institutions and governments during the last 200 years has been fully justified.

\section{Poxvirus recombinant vaccines}

Smallpox vaccination was always attended with some risks, and there was widespread relief when the eradication of smallpox led to the cessation of routine smallpox vaccination. However, in 1982 recombinant DNA technology was used to insert foreign genes into the genome of vaccinia virus [11]. The resultant recombinants are infectious, and if the gene inserted codes for the immunizing antigen of a microbial pathogen, the recombinant can be assessed as a potential vaccine the development of which would benefit from experience gained in the production and delivery of smallpox vaccine [10]. Too many vaccinia recombinant vaccines to list have been constructed and many have been tested in animal models and even small-scale human trials $[12,13]$. However, only two have been used in large-scale field trials. One is a recombinant rinderpest vaccine which has been tested in Africa and India [14]. The other is the recombinant rabies vaccine used for oral immunization of wild foxes, the major reservoir of rabies in Western Europe. The development, testing and large-scale use of this 
vaccine which has virtually eliminated rabies from Belgium is described in our first Special Article [5].

Although these recombinant vaccines are attenuated and apparently safe, concern persists about the use of vaccinia recombinant vaccines in humans or in animals in close contact with them. Such concern is caused by: the human pathogenicity of vaccinia which may have been underestimated in the past, the lack of a suitable model for human virulence, the wide host range of vaccinia virus, the potential dangers of using a live vaccine in populations in which HIV has a high incidence, and the possibility that the recombinant could become established in wildlife and even interact with other orthopoxviruses $[12,13,15,16]$. Adequate attenuation of the vaccinia vectors is essential, and further highly attenuated vaccinia recombinants with limited replication potential are being developed by specific deletion of genes concerned with host range and virulence functions $[6,17]$.

Another strategy, which avoids the human pathogenicity and wide host range of vaccinia virus, is to transfer experience gained with this virus to other poxviruses which are more host-specific. To this end raccoonpox recombinant rabies and capripoxvirus recombinant rinderpest vaccines are being developed $[18,19]$; the latter has the advantage that the recombinant vaccine also immunizes against lumpy skin disease the natural disease caused by the vector [19].

A further extension of the use of host-restricted poxvirus recombinants is the use of avipoxvirus recombinants as vectors for mammalian vaccines. Fowlpox and canarypox recombinant rabies viruses have been shown to immunize mammals against rabies and to elicit protective levels of rabies antibody in humans, even though the recombinants do not replicate in mammalian cells [20-22]. Such 'nonreplicating expression vectors' (NREV) have the benefits of traditional live attenuated vaccines in that the antigen is amplified and presented properly to all components of the immune system but, because they do not replicate, they also have the clinical and environmental advantages of non-infectious vaccines (Table 1). The development and testing of these poxvirus NREV is described in our second Special Article [6]. This also extends the discussion to the use of NREV developed from other viruses, and to the use of recombinant vaccines for gene therapy and in the control of cancer.

Despite the eradication of smallpox and uncertainty about the use of vaccinia recombinant vaccines, it is certain that poxvirus vaccines will play an increasingly important role in the control of a variety of diseases in the future.

\section{Derrick Baxby}

Department of Medical Microbiology,

University of Liverpool,

Liverpool $L 693 B X, U K$

\section{REFER ENCES}

1. Jenner E. An inquiry into the causes and effects of the variolae vaccinae. London: Sampson Low, 1798.

2. Baxby D. The genesis of Edward Jenner's Inquiry of 1798; a comparison of the two unpublished manuscripts and the published version. Med Hist 1985; 29: 193-9.

3. The Jenner centenary number. BMJ 1896; i: 1245-312.

4. Plotkin S, Fantini B, eds. Vaccinia, vaccination, vaccinology: Jenner, Pasteur, and their successors. Paris: Elsevier, 1996.

5. Pastoret PP, Brochier B. The development and use of a vaccinia-rabies recombinant oral vaccine for the control of wildlife rabies: a link between Jenner and Pasteur. Epidemiol Infect 1996; 116: 235-240.

6. Limbach KJ, Paoletti E. Non-replicating expression vectors: applications in vaccine development and gene therapy. Epidemiol Infect 1996; 116: 241-256.

7. Baxby D. Jenner's smallpox vaccine: the riddle of vaccinia virus and its origin. London: Heinemann Educational Books, 1981.

8. Jenner E. Further observations on the variolae vaccinae. London: Shury, 1799.

9. Dixon CW. Smallpox. London: Churchill, 1962.

10. Fenner F, Henderson DA, Arita I, Jezek Z, Ladnyj ID Smallpox and its eradication. Geneva: WHO, 1988.

11. Panicali D, Paoletti E. Construction of poxviruses as cloning vectors: insertion of the thymidine kinase gene from herpes simplex virus DNA into the DNA of infectious vaccinia virus. Proc Soc Natl Acad Sci USA 1982; 79: 7415-9.

12. Binns M, Smith GL, eds. Recombinant poxviruses. Boca Raton: CRC Press, 1992.

13. Baxby D. Recombinant poxvirus vaccines. Rev Med Microbiol 1993; 4: 80-8.

14. Yilma T, Hsu D, Jones L, et al. Protection of cattle against rinderpest with infectious vaccinia virus recombinants expressing the HA or F genes. Science 1988; 242: 1058-61.

15. Baxby D. Indications for smallpox vaccine: policies still differ. Vaccine 1993; 11: 395-6.

16. Baxby D, Gaskell RM, Gaskell CJ, Bennett M. Ecology of orthopoxviruses and use of recombinant vaccinia vaccines. Lancet 1986; ii: 850-1.

17. Tartaglia J, Perkus M, Taylor J, et al. NYVAC: a highly attenuated strain of vaccinia virus. Virology 1992; 188: 217-32.

18. Esposito JJ, Sumner JW, Brown D, et al. Raccoon poxvirus rabies-glycoprotein oral vaccine for wildlife; 
further efficacy studies and serosurvey for raccoon poxvirus. In: Brown F, Chanock RM, Ginsberg H, Lerner RA, eds. Vaccine '92. Cold Spring Harbor; Cold Spring Harbor Press, 1992; 321-9.

19. Romero $\mathrm{CH}$, Barrett $\mathrm{T}$, Chamberlin $\mathrm{RW}$, et al. Recombinant capripoxvirus expressing the hemagglutinin protein gene of rinderpest virus: protection of cattle against rinderpest and lumpy skin disease viruses. Virology 1994; 204: 425-9.
20. Taylor J, Weinberg R, Langhett B, Desmettre $P$, Paoletti E. Recombinant fowlpox virus induces protective immunity in non-avian species. Vaccine 1988; 6 : 497-503.

21. Cadoz M, Strady A, Meignier B, et al. Immunization with canarypox virus expressing rabies glycoprotein. Lancet $1992 ; 339$ : 1429-32.

22. Baxby D, Paoletti E. Potential use of non-replicating vectors as recombinant vaccines. Vaccine $1992 ; 10$ : 8-9. 